\title{
Using Solar Photovoltaic Energy for Irrigation: A Review of the Application
}

\author{
Bojan Đurin ${ }^{1}$, Shpetim Lajqi ${ }^{*}$, Lucija Plantak ${ }^{3}$ and Nikola Kranjčić ${ }^{3}$ \\ ${ }^{1}$ Department of Civil Engineering, University North, Croatia \\ ${ }^{2}$ Faculty of Mechanical Engineering, University of Prishtina "Hasan Prishtina", Kosovo \\ ${ }^{3}$ Faculty of Geotechnical Engineering, University of Zagreb, Croatia
}

\begin{abstract}
Modern agriculture, orcharding, gardening, as well as the use of grassy sports fields cannot be realized without irrigation. Such a procedure requires water and energy resources. Water resources define even consideration for the possibility of irrigation, while energy source is the second task which must be satisfied. Nowadays, using renewable energy sources for irrigation is a very promising solution, despite the still extensive use of fossil fuels. Application of the solar photovoltaic (PV) energy is a very promising solution, due to the availability of insolation and its overlapping with water needs for the plant growing. PV energy could be implied in isolated and remote locations and islands, as well as in desert areas. This paper will give insight into the actual "state of the art" of using solar photovoltaic energy for the purpose of the irrigation.
\end{abstract}

\section{Introduction}

When passing through the atmosphere, the solar radiation diminishes in intensity because it is partially reflected and absorbed (above all by the water vapor and by the other atmospheric gases). The radiation which passes through is partially diffused by the air and by the solid particles suspended in the air, Figure 1 [1].

Due to the review of the literature, real case studies, as well as scientific research, there are three types of the solar Photovoltaic (PV) water irrigation systems. These are PV irrigation systems without battery storage or water reservoir, PV irrigation systems with battery storage, and PV irrigation systems with water storage. Therefore, a combination of the last two is also possible. Also, PV irrigation systems could be "ongrid" or "off-grid". "On-grid" refers to the connection with the available electro-energy grid. "Off-grid" refers to the PV irrigation system which has full autonomy, without connection to the electro-energy grid. Considering the stated, presented material will give insight into the actual "state-of-the-art" of the application of the solar photovoltaic irrigation system.

\section{Parts of the Solar Photovoltaic Irrigation Systems}

\section{General description}

Figure 2 shows the most common components of PV water pumping systems. In general, the same parts could be used for configuration and operational work of the solar PV irrigation systems. Application of particular parts depends on the location, climate, population size, site characteristics, and the associated equipment.

Several modules mechanically and electrically connected form a panel, which is a common structure which can be anchored to the ground or to a building. Several panels electrically connected in series constitute an array and several arrays, electrically connected in parallel to generate the required power, constitute the generator or photovoltaic field, Figure 3 [1].

In most general form, PV driven pumping systems consist of the PV modules, power conditioner unit (inverter), motor and pump. The modules may be connected straight to DC motor, or to AC motor. Inverter is a device, which is used for transformation of $D C$ current into the $A C$ current, which is convenient for usage. For each $A C$ and DC systems, a battery bank can be utilized to save produced energy. Also, an alternative solution is saving the water into the water storage (reservoir). The motor will be coupled to any one of variable frequency drives. PV systems coupled with AC motors require DC/AC inverters. In complex PV systems, a backup system,

*Corresponding author: Shpetim Lajqi, Faculty of Mechanical Engineering, University of Prishtina "Hasan Prishtina", Kosovo

Accepted: November 30, 2020

Published online: December 02, 2020

Citation: Đurin B, Lajqi S, Plantak L, et al. (2020) Using Solar Photovoltaic Energy for Irrigation: A Review of the Application. Adv Environ Stud 4(2):358-367 


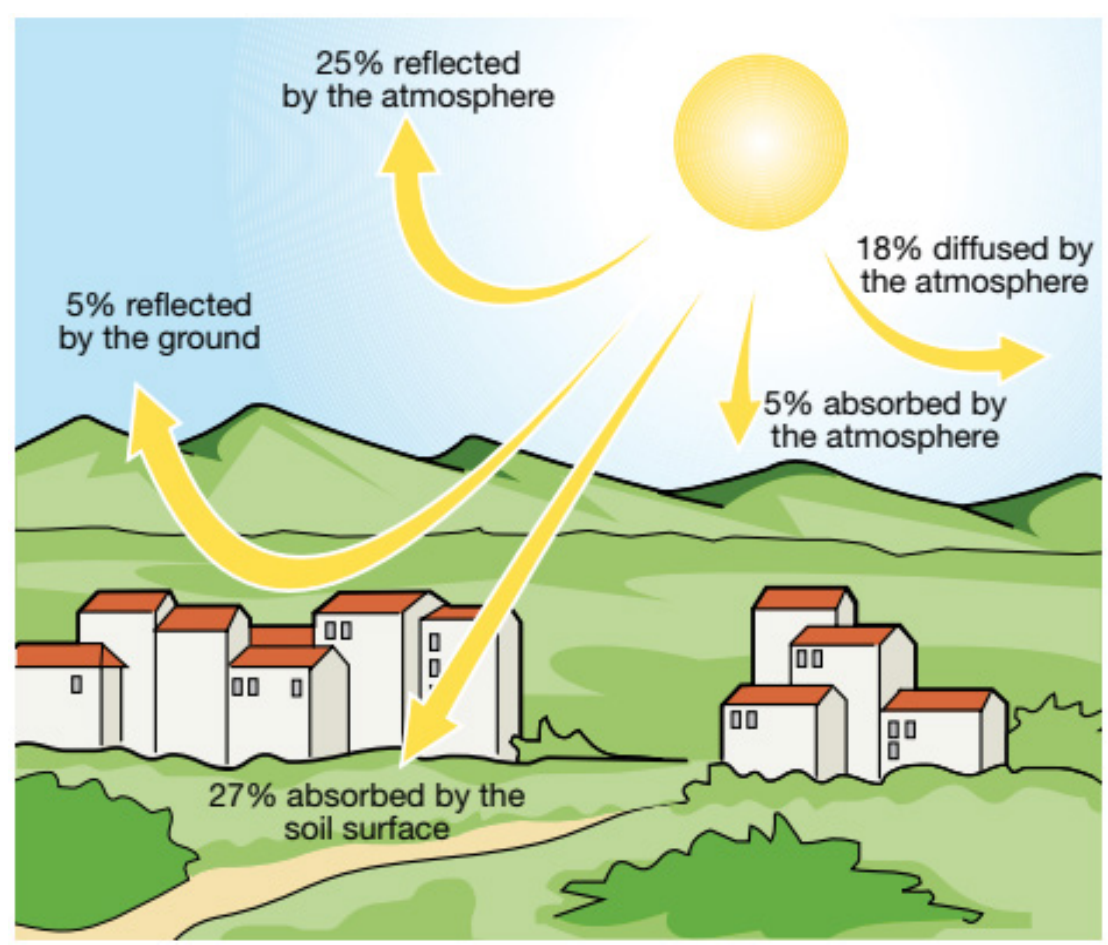

Figure 1: Energy flow (circle) between the Sun, the atmosphere and the ground.

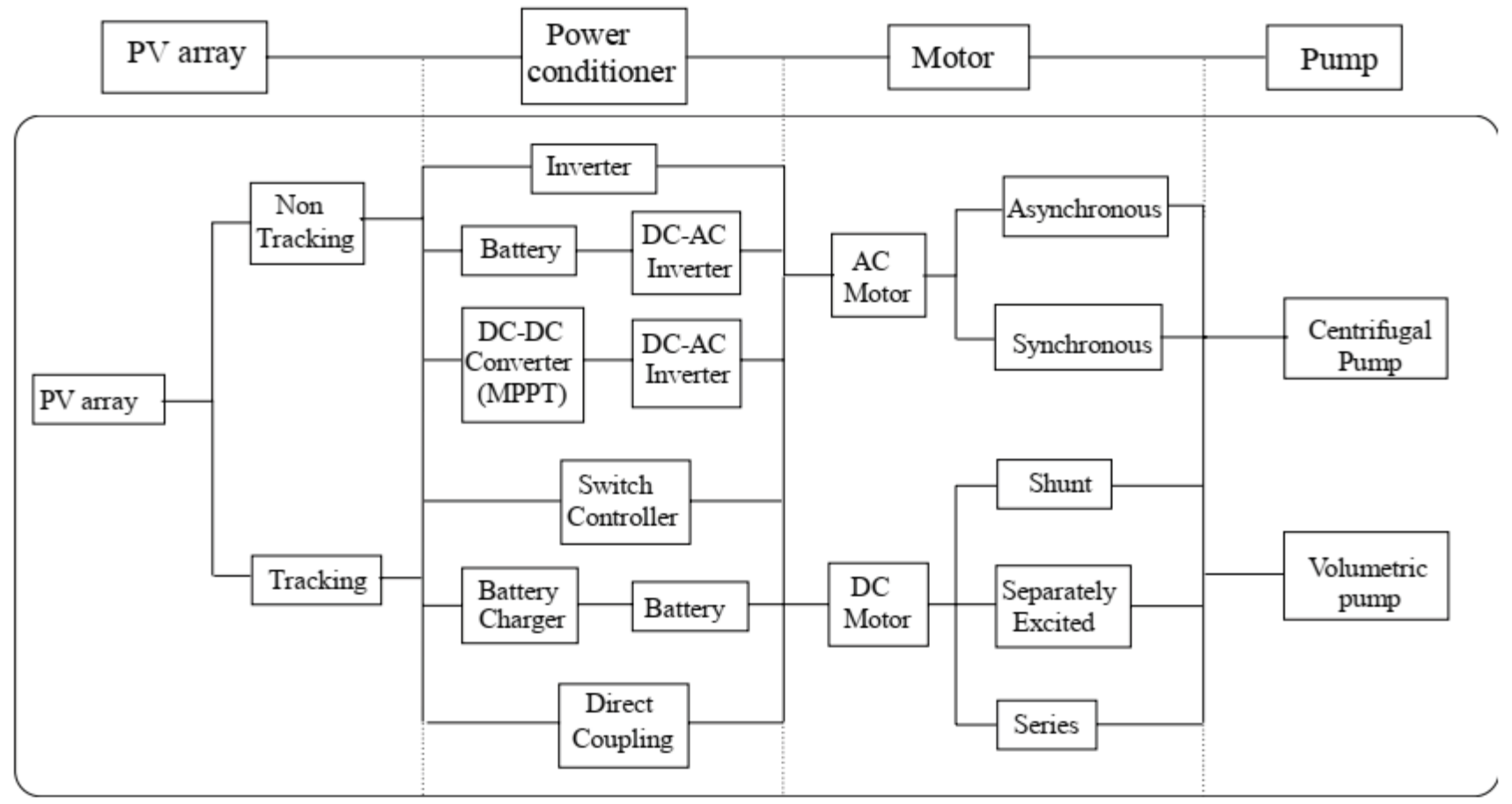

Figure 2: The most common parts of PV water pumping systems [2].

usually diesel generators, or connection with an electro distribution grid, are required as an additional source of energy for the case of lack of the insolation. This refers to cloudiness, or even for days without insolation. Generally, motors powered by PV are connected to any variable-speed (centrifugal) pump. Maximum power point tracking (MPPT) system scan be used to track the position of the Sun, i.e. to obtain maxi- mum power available from the PV panels. However, inverters are designed to being incorporated with an MPPT device, so that additional MPPT devices are not required. Role of the switch controller is controlling the solar battery (accumulator) overcharging [2].

Due to the purpose of this review paper, procedure for 


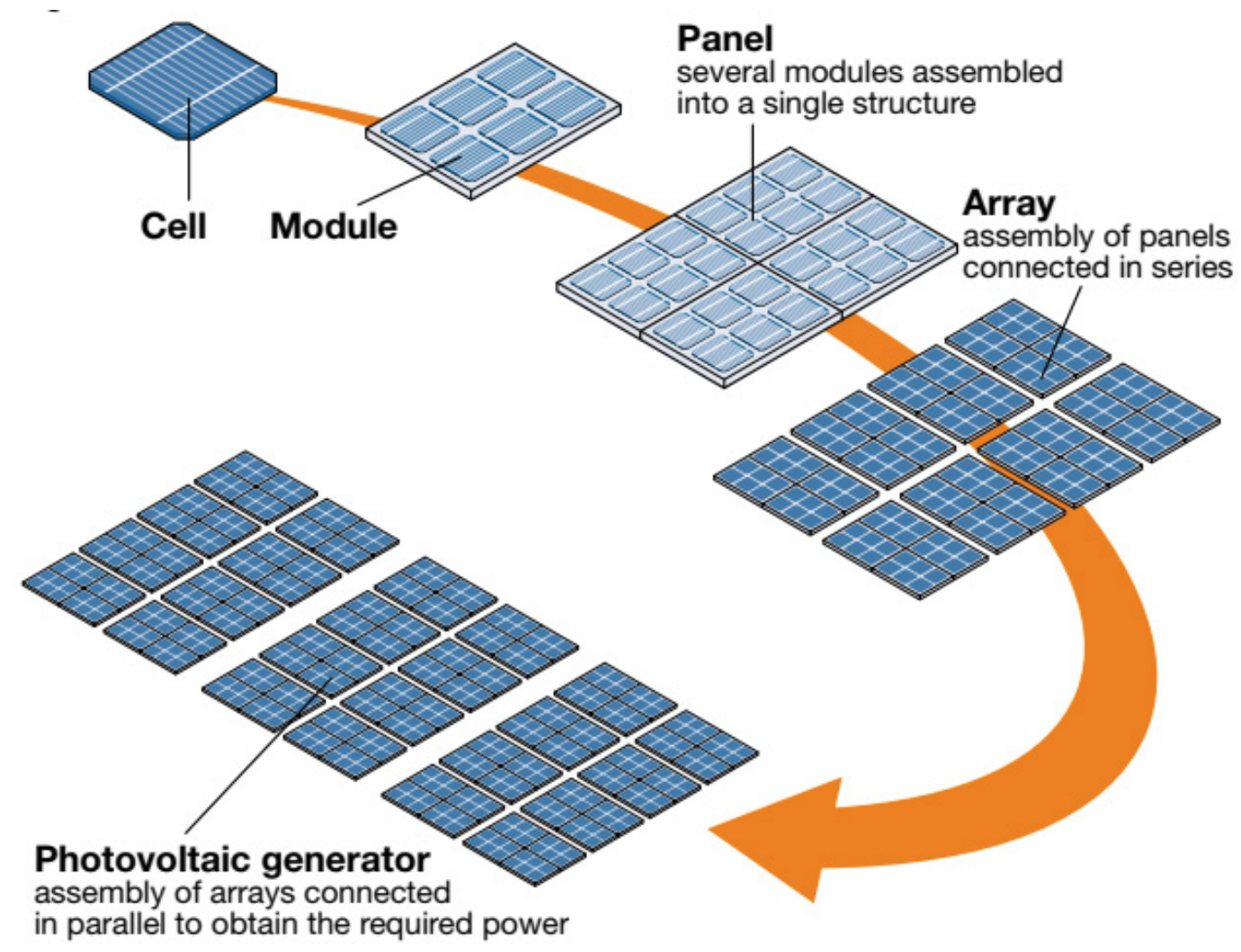

Figure 3: Main composing parts of the solar photovoltaic generator.

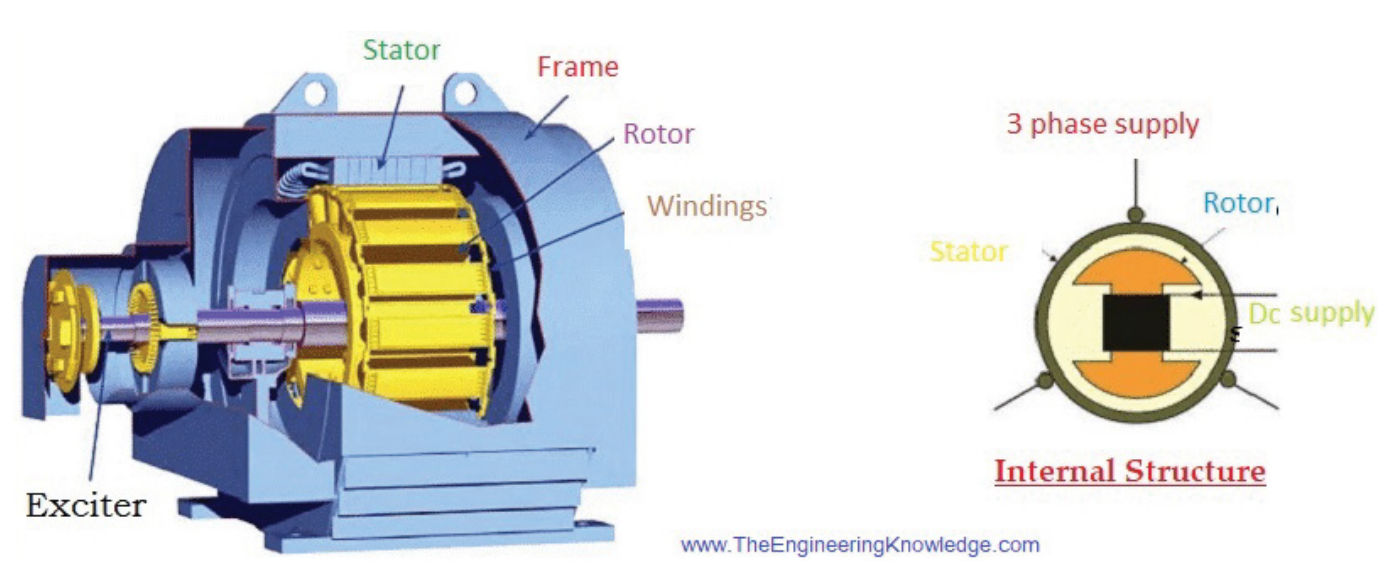

Figure 4: Synchronous motor [8].

sizing, as well as all required equations will not be written here, but they can be found in [3-6] where authors have in details explain all nomenclature, order and procedures for sizing of the solar photovoltaic irrigation systems. Such was done regarding different configurations of analyzed PV irrigation systems.

\section{Motors}

Generally, motors for pump driving can be divided as an $A C$ and DC motors. AC motors can be divided into two main categories; these are Synchronous and Asynchronous motor. Stator of the Synchronous motor has axial slots, which consist of a stator winding wound for a specific number of poles,
Figure 4. Generally, a salient pole rotor is used on which rotor winding is mounted. Rotor winding is fed with a DC supply with the help of slip rings. Rotors with permanent magnets can also be used $[7,8]$.

An asynchronous motor is also popularly called as Induction motor. At the Asynchronous or Induction motor, stator winding is similar to that of a synchronous motor. It is wound for a specific number of poles, Figure 5. A squirrel cage rotor, or a wound rotor can be used. In a squirrel cage rotor, the rotor bars are permanently short-circuited with end rings. In wound rotor, windings are also permanently short-circuited, hence no slip rings are required [7].

Stator poles of the synchronous motor rotate at the syn- 


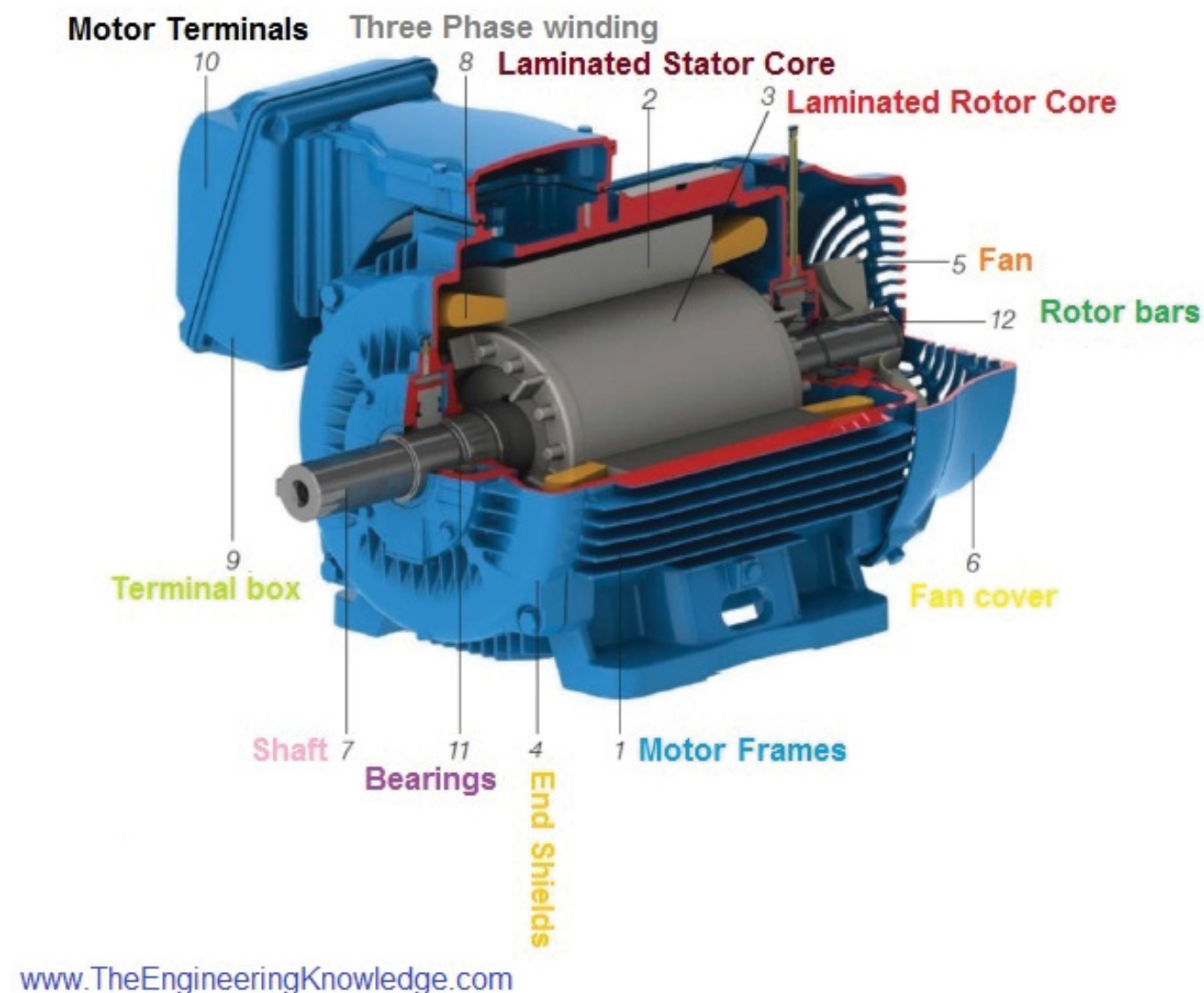

Figure 5: Asynchronous or Induction motor [8].

chronous speed when fed with a three-phase electric energy supply. The rotor is fed with a DC supply. The rotor needs to be rotated at a speed near to the synchronous speed during starting. If done so, the rotor poles get magnetically coupled with the rotating stator poles, and thus the rotor starts rotating at the synchronous speed. Regarding asynchronous motors, when the stator is fed with two or three phase AC supply, a Rotating Magnetic Field (RMF) is produced. The relative speed between the stator's rotating magnetic field and the rotor will cause an induced current in the rotor conductors. The rotor current gives rise to the rotor flux. According to Lenz's law, the direction of this induced current is such that it will tend to oppose the cause of its production, i.e. relative speed between stator's RMF and the rotor.

Thus, the rotor will try to catch up with the RMF and reduce the relative speed. Induction motor always runs at speed which is less than the synchronous speed $[7,8]$.

Synchronous motors require an additional DC power source for energizing rotor winding. Induction motors do not require any additional power source. Slip rings and brushes are required in synchronous motors, but not in Induction motors (except wound type induction motors in which slip ring motors are used to add external resistance to the rotor winding). Synchronous motors require additional starting mechanism to initially rotate the rotor near to the synchronous speed. No starting mechanism is required in induction motors. The power factor of a synchronous motor can be ad- justed to lagging, unity or leading by varying the excitation, whereas an induction motor always runs at a lagging power factor. Synchronous motors are generally more efficient than induction motors. Synchronous motors are costlier [7].

The main characteristics of a squirrel-cage induction motor are: Motor speed, slip, torque, and efficiency. In the following, each of these characteristics are written in more details [9]. The speed of a squirrel cage motor depends on the electric line frequency and the number of poles in the motor. The synchronous speed of motor is the design speed of the motor based on frequency and the number of poles. The stator windings can have any even number of pairs of poles. Most motor designs have between 2 and 12 pairs of motor poles. An induction motor's rotor must turn slightly slower than the stator's rotating magnetic field for a current to be induced into the rotor. The difference between the synchronous speed and the actual speed is known as slip. Motor torque is the work that a motor does and is defined as a force of one Newton a lever of one meter. The unit of measure is [Nm]. In current practice, motors tend to be between $80-95 \%$ efficient.

Motors usually achieve peak efficiency at around $75 \%$ of full load. The motor's efficiency will be significantly less at light loads. Care must be taken when replacing a motor to be sure that the replacement motor is not oversized, which causes reduced efficiency [9]. 


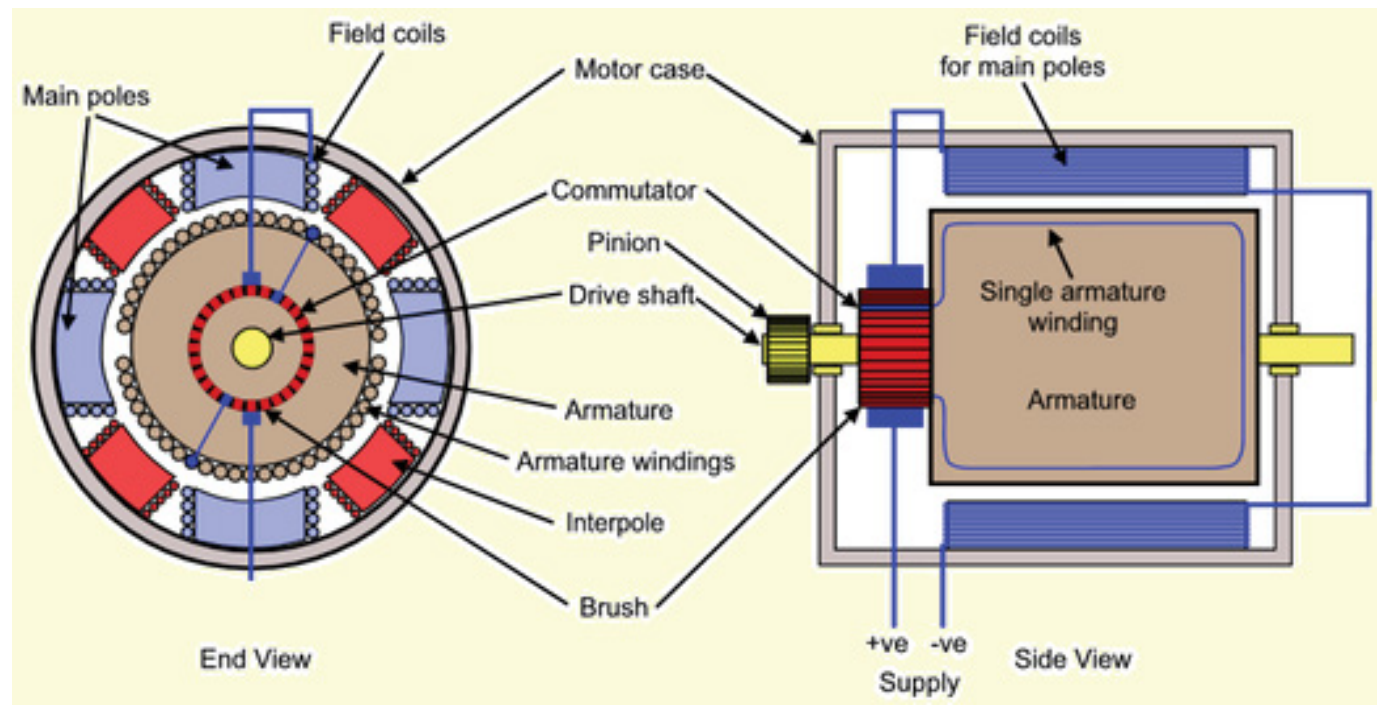

Figure 6: DC motor [10].

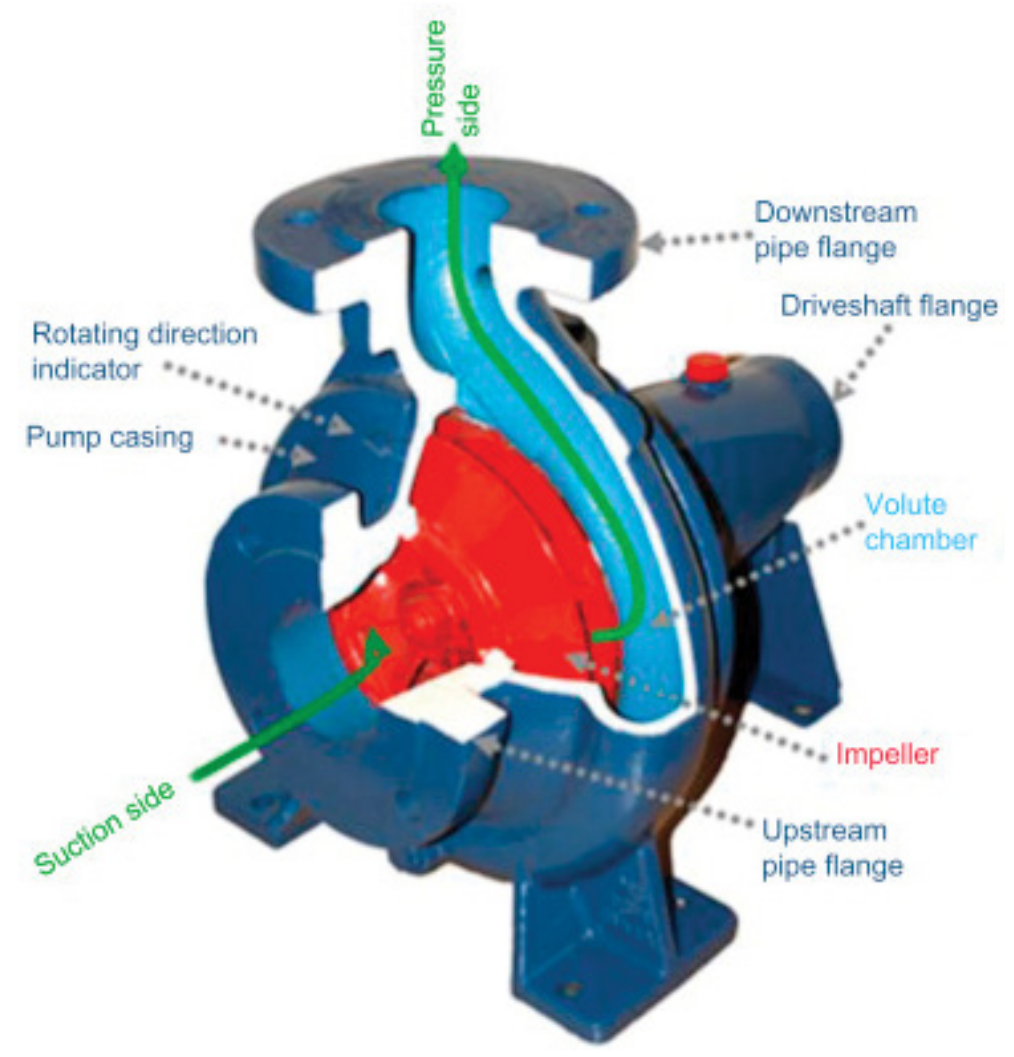

Figure 7: Centrifugal pump [14].

A DC motor consists of two basic parts - stator and rotor, Figure 6.

The outer frame of a DC machine is called a yoke. It is made up of cast iron or steel. It not only provides mechanical strength to the whole assembly but also carries the magnetic flux produced by the field winding. Poles are joined to the yoke with the help of bolts or welding. They carry field winding and pole shoes are fastened to them [10].
In a series DC motor, the field is connected in series with the armature. The field is wound with a few turns of large wire because it must carry the full armature current. A characteristic of series motors is the motor develops a large amount of starting torque. However, speed varies widely between no load and full load. Series motors cannot be used where a constant speed is required under varying loads. Additionally, the speed of a series motor with no load increases to the point where the motor can become damaged. Some 
load must always be connected to a series-connected motor. Series-connected motors generally are not suitable for use on most variable speed drive applications. The shunt-connected motor offers simplified control for reversing. This is especially beneficial in regenerative drives [11].

Separately excited DC motor motors also have both stator and rotor. Stator refers to the static part of motor, which consists of the field windings. And the rotor is the moving armature which contains armature windings or coils. Separately excited DC motor has field coils similar to that of shunt-wound DC motor. The name suggests the construction of this type of motor. Usually, in other DC motors, the field coil and the armature coil both are energized from a single source. The field of them does not need any separate excitation. But, in separately excited DC motor, separate supply is provided for excitation of both field coil and armature coil. The field coil is energized from a separate DC voltage source and the armature coil is also energized from another source. Armature voltage source may be variable but, independent constant DC voltage is used for energizing the field coil. So, those coils are electrically isolated from each other, and this connection is the specialty of this type of DC motor [12].

\section{Pumps}

Pump is a mechanical device used for transport of the fluid to the distanced points (locations), from lower to the higher elevation, for increasing the pressure, or for providing circulation of the fluid within the system. Regarding classification on Figure 2, as well as purpose of this paper, centrifugal and volumetric pumps will be topic of further discussion. The basic centrifugal pump consists of a rotating disk molded into vanes referred to as the impeller, Figure 7 . The impeller is encased in arousing to channel and direct the produced liquid flow. Water enters near the center of the impeller; whereby motion is imparted to the fluid through the rotation of the vanes and the water is then discharged through the outlet of the casing. By varying the particular designs and arrangements of centrifugal pumps, they can be constructed to suit specific needs or requirements [13].

Fluid enters the pump through the intake and reaches the impeller along, or near to, the rotating axis. It is accelerated by the impeller before flowing outwards through a diffuser or volute chamber. The pressure increases or the head of fluid that can be lifted by a single impeller is limited. Some centrifugal pumps will use several impellers and diffusers in series, with each impeller/diffuser stage increasing fluid pressure by a set amount. When combined the head of fluid that can be lifted becomes significant [14].

More suitable for well are centrifugal multi step Submersible Pump, Figure 8 [15].

Volumetric Pumps use volume variation within a chamber to create suction and thrust of a fluid, Figure 9 [16].

The fluid is first sucked into the chamber, creating a vacuum therein and then expelled from the chamber, thus increasing the pressure inside it. For example, the heart of a mammal is a volumetric pump. Volumetric pumps move constant volumes of liquid for each operating cycle since the chamber has a maximum defined and invariable volume. One operating cycle corresponds to a complete rotation $\left(360^{\circ}\right)$ of the drive shaft. The volume pumped per unit of time $(1 / \mathrm{min}$ or $\mathrm{gpm}$ ) is independent of the fluid pressure, while it is directly proportional to the pump speed (number of rpm) [17].

\section{Solar Photovoltaic Irrigation Systems}

\section{Solar photovoltaic irrigation systems without battery storage or water reservoir}

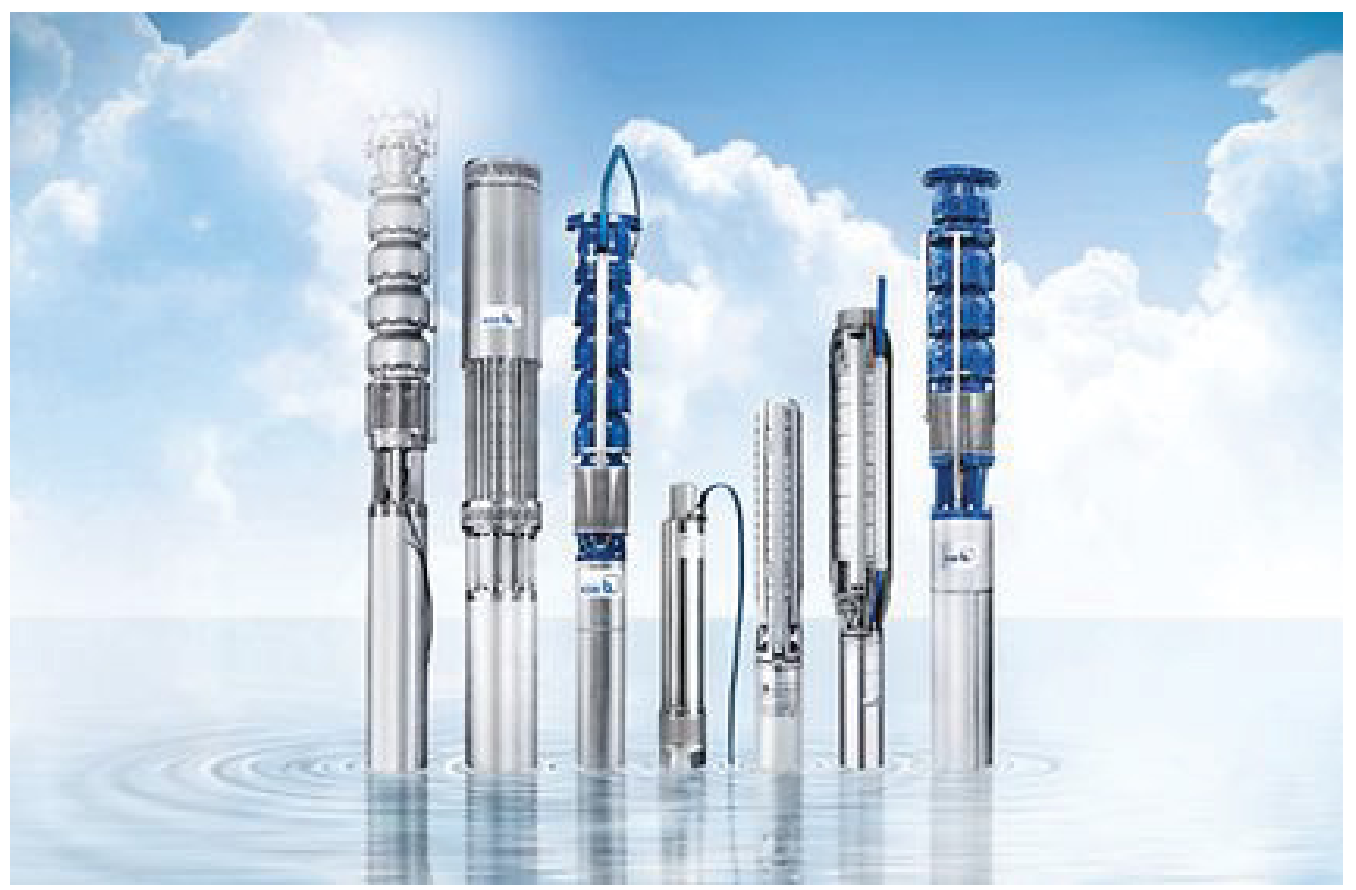

Figure 8: Centrifugal multi step Submersible Pump [15]. 


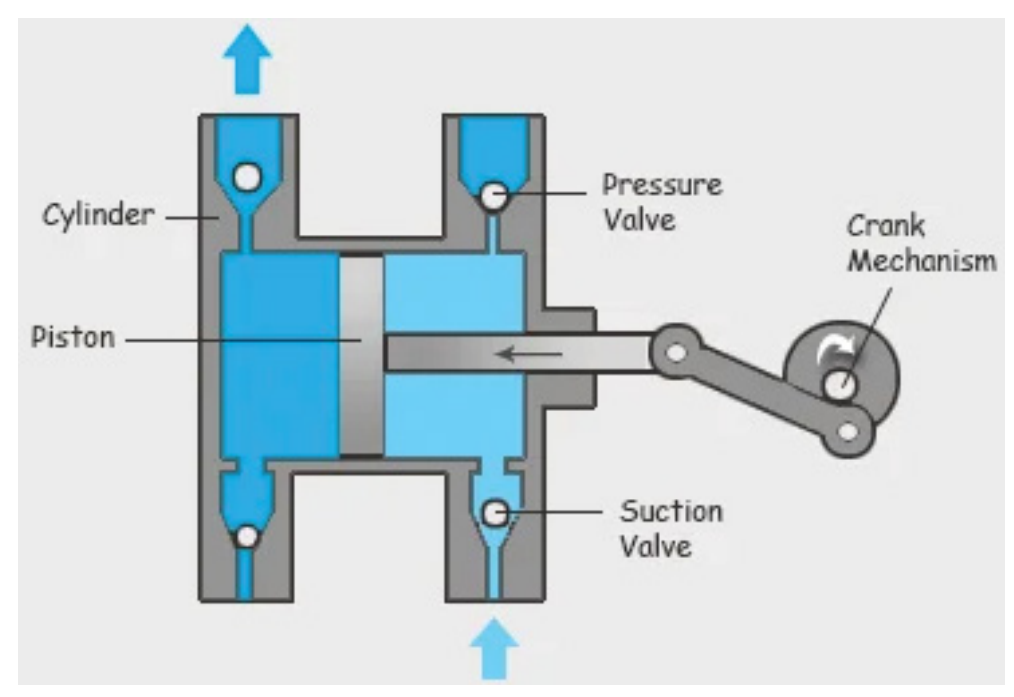

Figure 9: Volumetric pump [17].

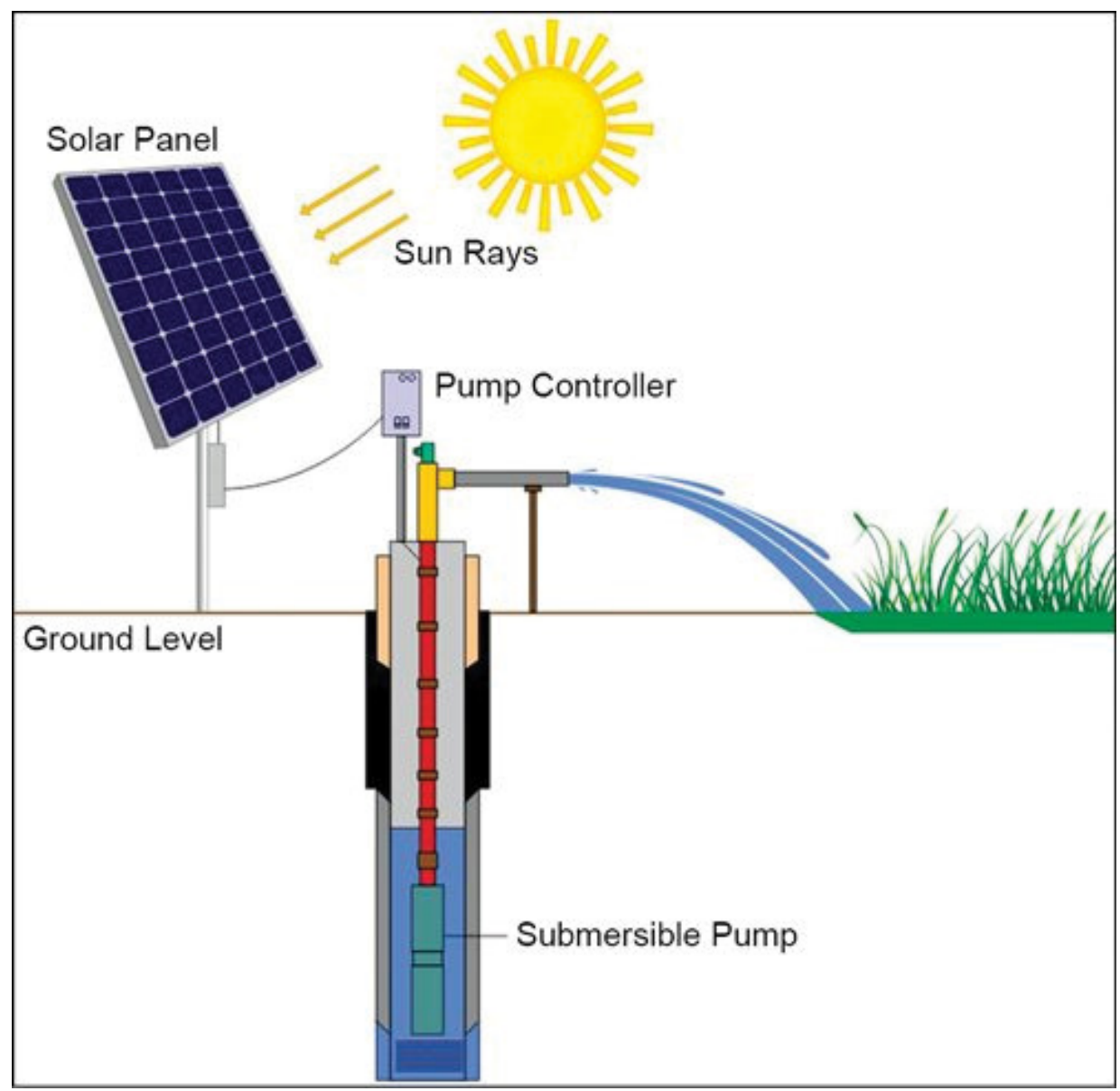

Figure 10: Example of configuration of the solar photovoltaic (PV) irrigation system without battery storage or water storage [18].

Figure 10 shows the most common configuration of the solar PV irrigation system without battery storage or water storage. This is the simplest version, which is usually used for local irrigation [18].

Water is taken from water sources, which can be underground water, water from rivers, lakes or even collected rainwater. By the pump, water is pumped to the remote or higher location where the irrigation field is located. Demerit of the presented irrigation system is the truancy of the water flow when insolation intensity (amount and duration) is not enough for driving the pump (station), for example during cloudiness, or during the night. On Figure 11, an example of the built PV irrigation system without battery storage or water reservoir could be seen [19]. 


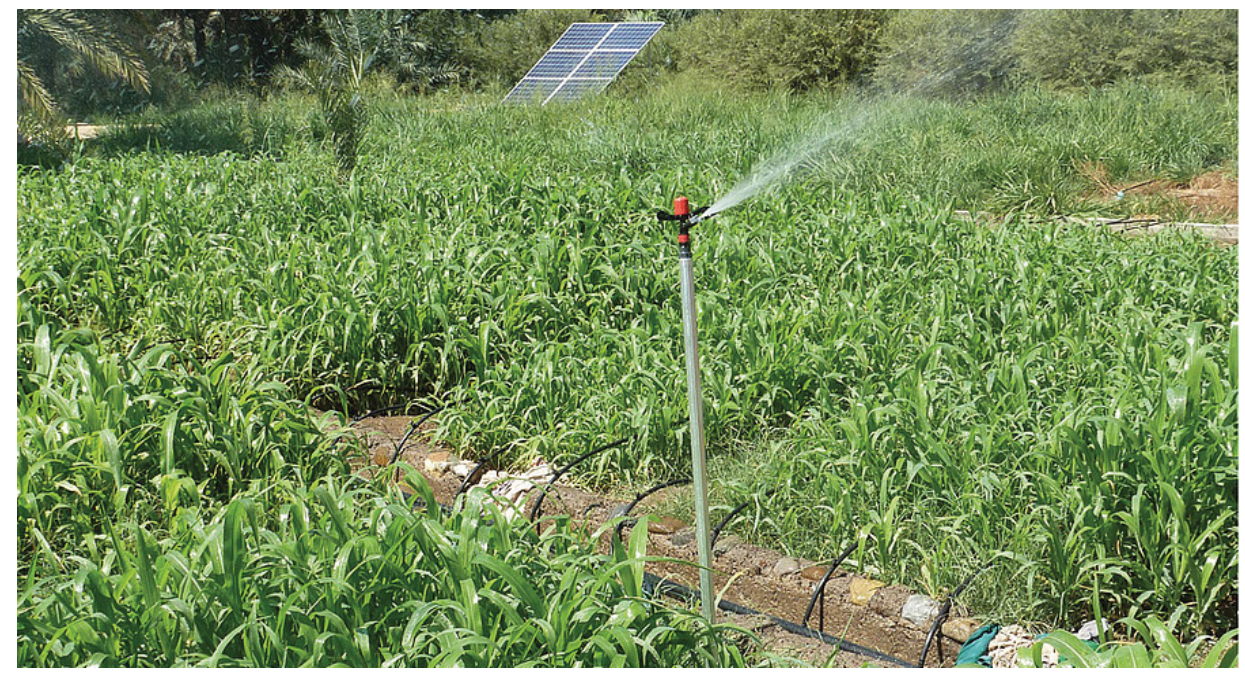

Figure 11: Example of the built PV irrigation system without battery storage or water reservoir [19].

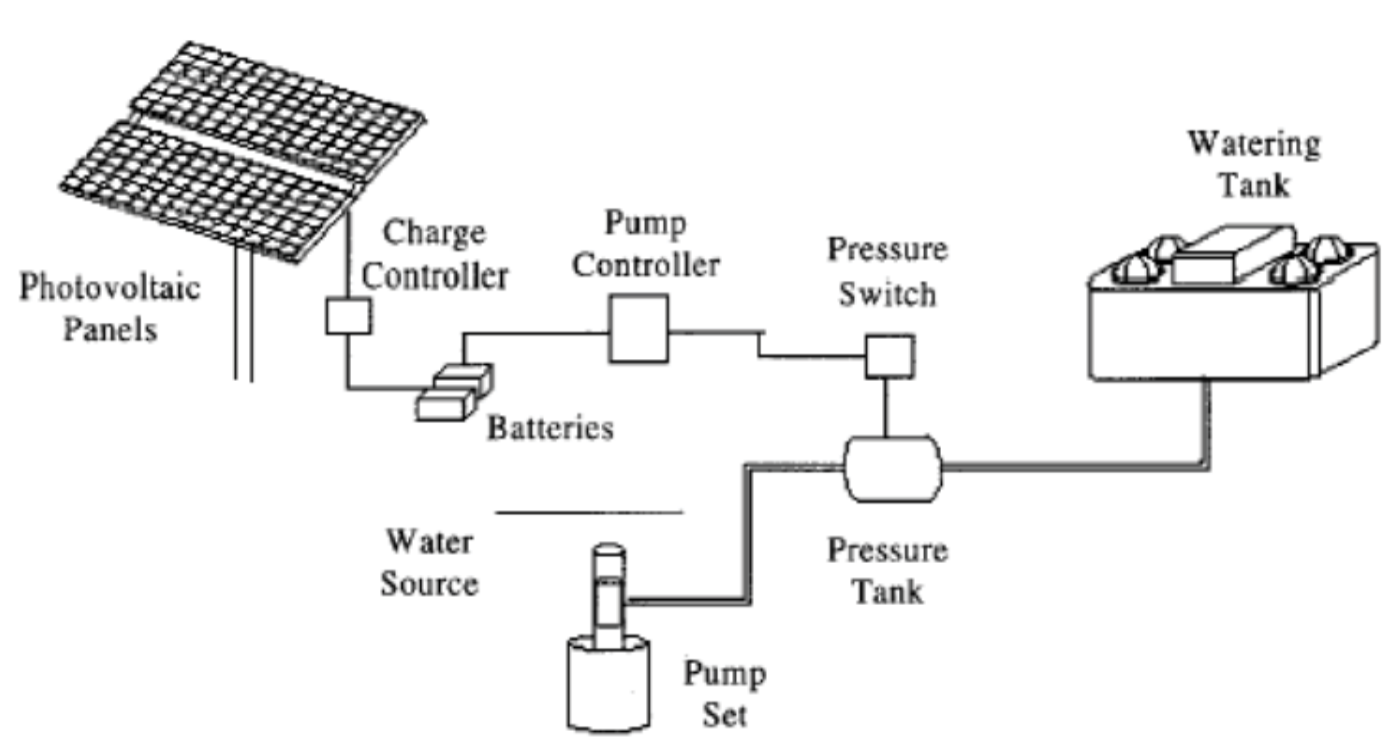

Figure 12: Example of the built PV irrigation system with battery storage or without water reservoir [20].

Solar photovoltaic irrigation systems with battery storage

Figure 12 presents the most common configuration of the PV irrigation system with battery storage [20]. Such PV irrigation systems provide autonomy and continuity of the operational work of PV irrigation systems, due to the stored energy in solar batteries. By taking this into consideration, there is possibility for irrigation at desired period.

\section{Solar photovoltaic irrigation systems with water reservoir}

Usual configuration of the solar photovoltaic (PV) irrigation system with water reservoir is shown on Figure 13 [21].

Water is pumped into the water reservoir through operational work of the pump through available insolation. By this way, stored water could be used in periods when the pump is not working. Prerequisite for using the water from water storage is sufficient pressure for distribution of the water. An Example of the built PV irrigation system with water reservoir is presented on Figure 14 [22].

\section{Conclusion}

Presented materials and facts show insight into the wide possibility of the usage of solar photovoltaic (PV) irrigation systems. For remote, as well as for the isolated areas, especially islands, PV irrigation systems have full justification of their installation and usage. All parts of the solar Photovoltaic irrigation systems are shown and explained on the level, which could be understood at the beginner, as well as expert level of the engineering knowledge. It could be concluded that a solar PV irrigation system with battery storage provides the biggest reliability of the water distribution continuity. Reliability of the water distribution of the solar PV irrigation systems with water reservoirs depends on the possibility of the providing of adequate pressure, which always cannot be 


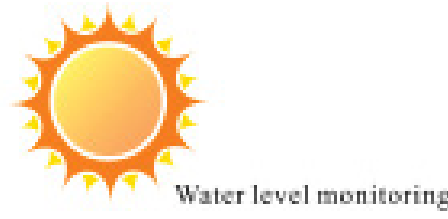

\section{PV array}

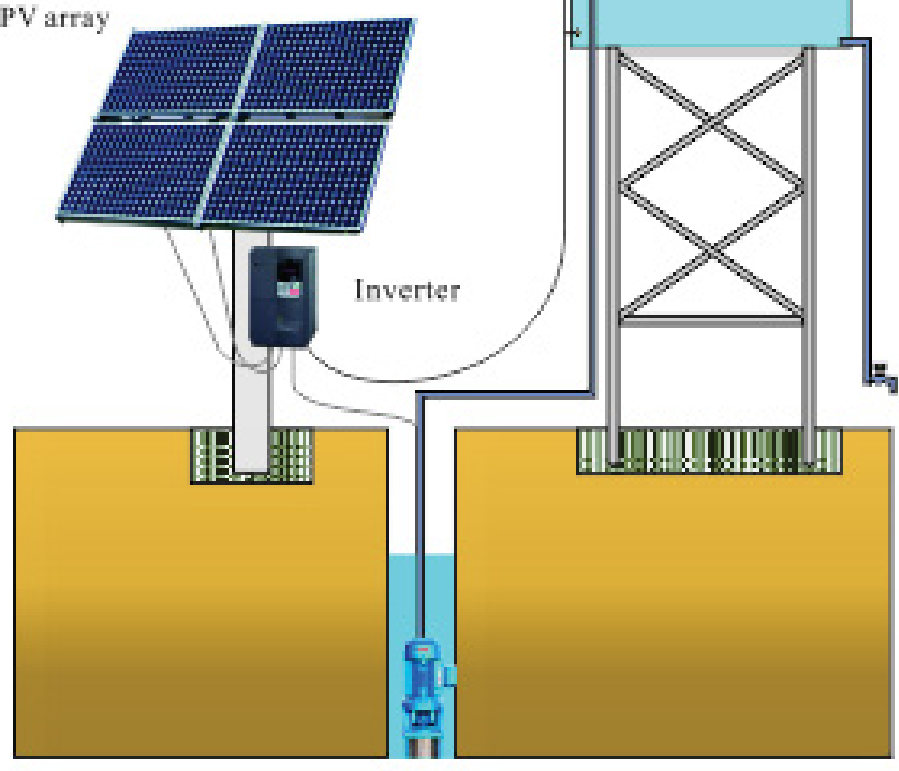

Water pump

Figure 13: Configuration of the PV irrigation system with water reservoir [21].

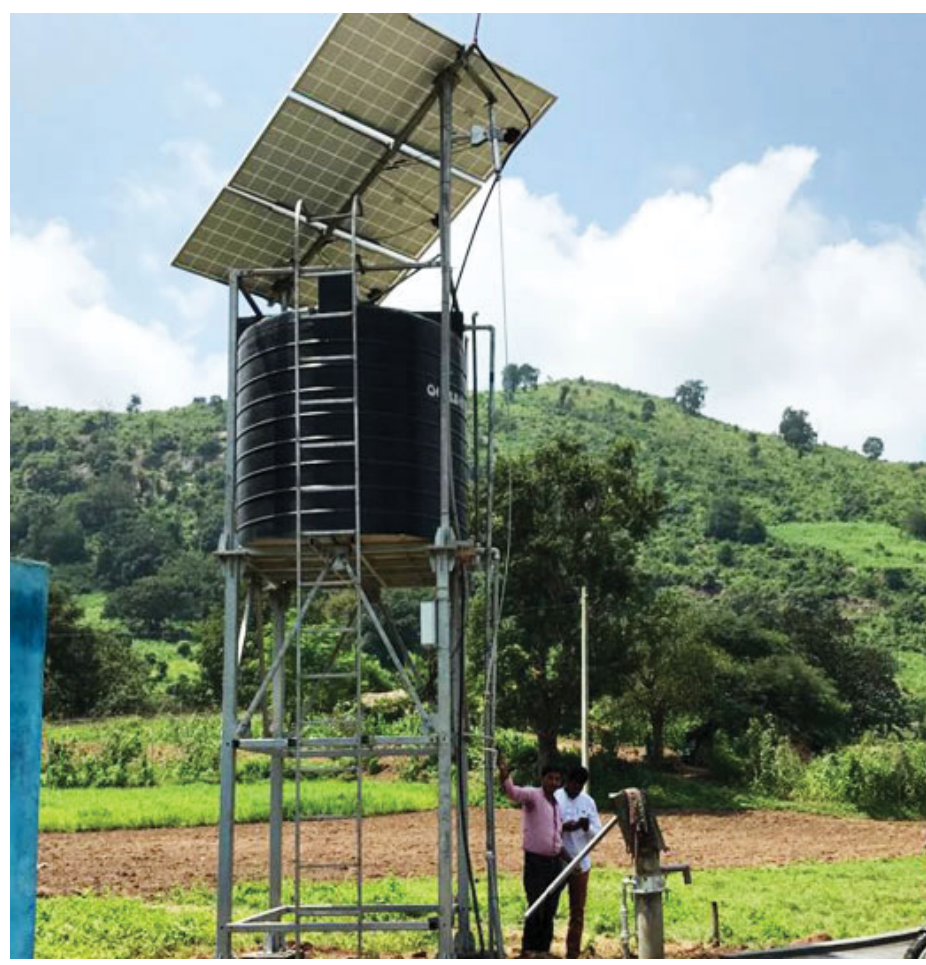

Figure 14: Built PV irrigation system with water reservoir [22]. 
satisfied. The simplest solar PV irrigation systems without any storage could be used only during appropriate insolation.

\section{References}

1. (2010) Technical application papers no.10 photovoltaic plants. ABB SACE.

2. Argaw N (2004) Renewable energy water pumping systems handbook. Denver, Colorado.

3. Đurin B (2014) Sustainability of the urban water supply system operating. Faculty of Civil Engineering, Architecture and Geodesy, University of Split.

4. Borisov B, Đurin B, Matin J (2016) The concept of sustainable irrigation on the example of football field of F.C. "Obreš", Sveti Ilija, Croatia. Inženjerstvo okoliša 3: 71-81.

5. Đurin B, Lajqi S, Plantak L (2018) 'Worst month' and 'critical period' methods for the sizing of solar irrigation systems-A comparison, Revista Facultad de Ingeniería Universidad de Antioquia, 100-109.

6. Đurin B, Baić $L$ (2018) The method of selecting the optimal variant of irrigation systems driven by PV energy, American Scientific Research Journal for Engineering, Technology and Sciences 26: 225-243.

7. Daware K (2015) Difference between synchronous motor and induction motor. Electrical Easy.

8. Henry (2020) Introduction to synchronous motor. Eng Knowl.
9. Lee Layton PE (2012) Written pole motors. PDH Online.

10. Raj S (2017) Construction and working of DC motor. Electricals.

11. Team MCOM (2017) 4 types of DC motors and their characteristics. Motion cotrol Mot Blog.

12. (2018) Separately excited DC Motor. Basic Electronics Tutorials.

13. Nolan DP (2011) Fire fighting pumping systems at industrial facilities. $2^{\text {nd }}$ edn, Elsevier.

14. Crumpton H (2018) Well control for completions and interventions. Gulf Professional Publishing.

15. KSB (2020) Daily in action: KSb's versatile submersible borehole pumps.

16. Web D (2019) Basics of positive displacement pumps. Worldwide Hydraulic Professionals.

17. (2019) Pumping systems: Types of pumps. COMET.

18. Theo S (2014) Solar-powered irrigation systems. Electronicsforu. com.

19. (2015) PV irrigation system for Omani farmers. Phaesun.

20. Buschermohle MJ, Burns RT (2020) Solar - powered livestock watering systems. Agricultural Extension Service, The University of Tennessee.

21. (2018) The application of PI9000-S series solar pump inverter on photovoltaic water pump. POWTRAN.

22. (2020) About solar energy. Gramodaya Energy.

DOI: $10.36959 / 742 / 232$

Copyright: (C) 2020 Đurin B, et al. This is an open-access article distributed under the terms of the Creative Commons Attribution License, which permits unrestricted use, distribution, and reproduction in any medium, provided the original author and source are credited. 